the open and across the snow, where it was quickly caught, for keeps this time. After sitting on the rabbit for a minute, the eagle commenced feasting on its prey. It is interesting to ncte that the rabbit managed to escape from the eagle's grip twice during the early stages of the chase. Why? One can only speculate, but three possibilities occur to me. It was a bitterly cold day with a strong wind and the wind might have affected the eagle's hold on the rabbit by upsetting its balance. The eagle was an immature and thus probably not exper- ienced in capturing rabbits. The rabbit appeared big and healthy and may have been nearly too heavy for the young eagle.

These observations of predation by eagles are supported by accounts in A. C. Bent's Life Histories of North American Birds of Prey; Golden Eagles were recorded taking a fourpoint White-tailed Deer, Pronghorn, and foxes.

I would like to thank Dr. R. F. B. King, Dean of the Faculty of Arts at Brandon University, for his assistance with this article.

\title{
COLLECTIVE PARENTAL CARE BY TREE SWALLOWS
}

\section{by Wayne Miller, 2 Almond Crescent, Brandon, Manitoba}

On July 3, 1966 Mr. John Lane noted two male Tree Swallows (Iridoprocne bicolor) feeding nestling swallows in a nest box several miles south of Chater, Manitoba. Mr. Lane took photographs in order to record this unusual incident of two males attending the same nest. A year later I made similar and related observations which form the basis for this note.

On July 16, 1967, at nest box 902 (Brandon Junior Birders' Nest Project) located to the northwest of Oak Lake, seven adult swallows defended the three-day-old young upon my close approach to the site. Three days later (July 19) when an Eastern Kingbird (Tyrannus tyrannus) perched near the box, a female swallow vigorously pursued it, urged on by two male swallows. Both of the latter then took flight and escorted the female back to the box, at which time a second female entered the nest. The intruding pair of swallows appeared strongly possessive and finally the "proper" male gave chase, apparently confused as to which was his mate, for a third female had appeared on the scene and had entered the box.

At ancther site south of this location, also near Oak Lake and on the same date, nine adult swallows (six males and three females) were found perched at nest box 1159. These birds were all aiding the six fully-fledged young to fly, and were coaxing the remaining three young from the box. I took one bird from the nest and released it, whereupon it took flight for the first time, followed and assisted by four adult male swallows.

I suspect, judging by the above observations, that for various reasons, including a scarcity of nesting cavities, many pairs of swallows are unable to nest, or have had an unsuccessful nesting. These birds, which retain the parental instinct, encroach on nesting pairs and aid with the parental duties, including feeding of the young and defense of the nest.

EDITOR'S NOTE: Volume two of "Studies in the life history of the Song Sparrow" (Dover edition, 1964), by Mrs. Margaret M. Nice, contains a discussion of this subject under the title: "Helpers at the nest." A variety of species have been observed responding to the begging behaviour of young of other species by feeding them. "Unmated helpers" of the same kind are also frequent and in some species one or more helpers occur fairly regularly. Extra birds of either sex have been previously recorded, for example, feeding at nests of the Tree Swallow, European Barn Swallow (Hirundo rustica), and Violet-green Swallow (Tachycineta thalassina). It would be valuable and instructive to have further observations of this interesting behaviour in the Tree Swallow, particularly if it were possible to follow the details of its development in a given situation. 